\title{
Effect of Thickening Powder on Gastrointestinal Losses in Patients With High-output End Jejunostomy Syndrome - Preliminary Results
}

\author{
ZUZANNA ZACZEK ${ }^{1,2}$, KAROLINA DĄBROWSKA ${ }^{2}$, MOHAMMAD OMIDI $^{2}$, \\ MARIUSZ PANCZYK ${ }^{3}$ and JACEK SOBOCKI ${ }^{2}$ \\ ${ }^{1}$ Department of Human Nutrition, Faculty of Health Sciences, Medical University of Warsaw, Warsaw, Poland; \\ ${ }^{2}$ Department of General Surgery and Clinical Nutrition, \\ Centre of Postgraduate Medical Education, Warsaw, Poland; \\ ${ }^{3}$ Department of Education and Research in Health Sciences, \\ Faculty of Health Sciences, Medical University of Warsaw, Warsaw, Poland
}

\begin{abstract}
Background/Aim: End jejunostomy syndrome is a type of short bowel syndrome (SBS) in which the jejunum forms the end of the bowel, as a result of resection or exclusion of the ileum and colon. It is associated with a high risk of dehydration, electrolyte imbalance, and malnutrition due to excessive stomal losses. Patients and Methods: In this retrospective study, we analyzed the medical records of sixteen adult patients with SBS and high-output end jejunostomy syndrome who received thickened fluids during their hospitalization in the home parenteral nutrition unit. The main parameter considered was daily stoma excretion volume, measured by 24-h collection. Values were compared between days when patients drank the daily amount of $600 \mathrm{ml}$ of water, and days when patients ingested the same amount of water but mixed with thickening powder to achieve a mildly thick consistency. Results: Median volumes of end jejunostomy output were significantly lower when patients consumed the mixture of water and thickening powder, compared with drinking water without additives (550.0

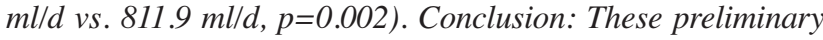
results demonstrate a potential benefit of thickening powder for the nutritional management of patients with SBS type I, and point to the need for further randomized clinical studies with larger patient groups.
\end{abstract}

This article is freely accessible online.

Correspondence to: Zuzanna Zaczek, Department of Human Nutrition, Faculty of Health Sciences, Medical University of Warsaw, Erazma Ciołka 27, 01-445 Warsaw, Poland. Tel: +48 225841320,e-mail: zuzanna.zaczek@wum.edu.pl

Key Words: End jejunostomy syndrome, thickening powder, high output stoma, short bowel syndrome management, nutrition.
End jejunostomy syndrome refers to a condition following surgical resection or structural or functional exclusion of the ileum and colon, in which jejunum forms the end of the intestine (1). It is considered the type of SBS associated with the highest risk of total parenteral nutrition (TPN) dependence, as it leads to the most severe malabsorptive complications compared to other SBS types $(2,3)$. Patients with end jejunostomy are most likely to develop high output stoma (HOS) $(4,5)$. Due to a significant shortening of the jejunum, its poorer adaptability after resection (compared to that of the ileum) and impaired neuroendocrine "ileo-colonic brake" leading to accelerated gastrointestinal motility, the secretion of fluids and electrolytes in this group of patients tends to extend the absorption ('net secretors'), putting them at risk of dehydration and dyselectrolytaemia (2, 6, 7). Further consequences of electrolyte depletion and nutrient malabsorption in high output end jejunostomy patients include malnutrition, renal and hepatic complications, gallstones, and secondary osteoporosis $(2,8,9)$. In addition, the end jejunal anatomy of the remaining bowel is considered a risk factor for mortality related to short bowel syndrome (1). Accurate definition of the incidence of both SBS and end jejunostomy syndrome is difficult, and available estimates are mostly based on the number of patients receiving total parenteral nutrition. According to available data, the prevalence of SBS in European countries varies between 0.4 and 30 cases per million $(10,11)$. High-output stoma occurs in up to $17 \%$ stoma patients and is most commonly associated with the formation of end jejunostomy (5). Treatment principles include restriction of oral intake (especially of hypo- and hypertonic fluids, with solid, salty foods better tolerated), and use of antimotility (e.g., loperamide) and antisecretory agents (e.g., $\mathrm{H} 2$ receptor antagonists, racecadotril, proton pump inhibitors) to slow the intestinal transit and decrease gastric secretion $(3,12,13)$. 
Thickening powders (TPs) are commonly used to adjust the consistency of solid foods and fluids to swallowing abilities in patients with dysphagia, and therefore alleviate the risk of choking and aspiration pneumonia. They are classified as foods for special medical purposes (FSMP) and their primary purpose is to enhance the safety and efficacy of swallowing in patients with dysphagia $(14,15)$.

The study aimed to evaluate the impact of thickening powders on reducing stoma output in individuals with short bowel syndrome and HOS, and therefore their possible use in the nutritional management of end jejunostomy syndrome. To our knowledge, this study is the first attempt for such use of thickening powders.

\section{Patients and Methods}

Study design and patient population. This retrospective observational study included sixteen patients ( 9 male and 7 female) hospitalized in the home parenteral nutrition (HPN) unit. The inclusion criteria were as follows: age $\geq 18$ years, proven diagnosis of short bowel syndrome, functional high-output end jejunostomy syndrome (defined as stoma output $>$ diuresis), and administration of thickened fluids during hospitalization (according to the scheme presented in Section "The scheme of thickening powder supplementation"). The underlying conditions of SBS were: surgical complications $(n=10)$, Crohn's disease $(n=3)$, vascular etiology of intestinal necrosis $(n=2)$, intestinal obstruction $(\mathrm{n}=1)$.

Data collection and analysis. Patients' medical records were analyzed and the following data were collected: age, weight, height, SBS-related diagnosis, and 24-h stomal output values.

Body mass index (BMI) was calculated by dividing body weight $(\mathrm{kg})$ by height $(\mathrm{m})$ squared. The values were classified into three categories - underweight, normal weight, and overweight. Depending on the age of the participants, the Centers for Disease Control and Prevention (CDC) (16) cutoff values were used for individuals aged $<65$ yo, and for seniors ( $\geq 65$ yo), the ranges suggested by Lipschitz (17) were applied. The reference ranges for BMI are shown in Table I.

The scheme of thickening powder supplementation. At the baseline, patients spent between 5 and 12 days in the hospital ward. All patients received only tailored total parenteral nutrition infused for $16-20 \mathrm{~h}$ per day. For the first four days (stage I - "W") patients were allowed to drink $600 \mathrm{ml}$ of room temperature still mineral water per day. The daily amount of water was divided into three glasses of $200 \mathrm{ml}$ each. Patients were instructed to sip the water slowly so that drinking a glass of water would last approximately $3 \mathrm{~h}$. Over the next four days (stage II - "W+TP"), patients were given three identical glasses, this time with the mixture of water and thickening powder available on the European market. The ingredients of the powder were as follows: maltodextrin, xanthan gum, guar gum. According to the manufacturer's package insert, it is resistant to oral amylase, therefore its consistency remains stable when consumed. Moreover, it does not affect the organoleptic values of foods and liquids. The mixture was prepared according to the manufacturer's instructions to achieve mildly thick (level 2) consistency according to the International Dysphagia Diet Standardisation Initiative (IDDSI) framework (18). Two level scoops of thickening powder were mixed with $200 \mathrm{ml}$ of
Table I. Reference ranges of body mass index (BMI).

\begin{tabular}{lcclccc}
\hline BMI $\left[\mathrm{kg} / \mathrm{m}^{2}\right]$ & \multicolumn{2}{c}{ AGE $<65 \mathrm{yrs}$} & & \multicolumn{2}{c}{ AGE $\geq 65 \mathrm{yrs}$} \\
\cline { 2 - 3 } \cline { 6 - 7 } & MIN & MAX & & MIN & MAX \\
\hline Underweight & - & 18.49 & & - & 21.99 \\
Normal weight & 18.50 & 24.99 & & 22.00 & 26.99 \\
Overweight & 25.00 & - & & 27.00 & - \\
\hline
\end{tabular}

still water (room temperature) and stirred thoroughly with a fork. TP was first added to the glass first, then the water was added as indicated by the producer. The recommendations regarding the timing of intake remained unchanged compared to the first stage. Daily stoma output volumes were measured by 24 -h collection. Patients also provided a subjective assessment of the density of stoma discharge. The graphical presentation of the scheme can be found in Figure 1.

Statistical analysis. Quantitative and categorical variables are described with descriptive statistical methods. For quantitative variables, the following measures were determined: Central tendency (median, Mdn) and dispersion (semi-quartile range, $\mathrm{IQR} / 2$ ). For the categorical variables, the following measures were determined: Number $(\mathrm{N})$ and frequency $(\%)$.

Cross-tables and a Fisher-Freeman-Halton exact test were used to assess differences between categorical variables. To assess differences between female $v s$. male group, Mann-Whitney $U$-test with continuity correction was used. The Wilcoxon signed-rank test with eta-squared effect size coefficient were used to compare volumes after drinking water and the mixture of water with thickening powder.

All calculations were performed with STATISTICATM 13.3 software (TIBCO Software, Palo Alto, CA, USA). For all analyses, a $p$-level of $<0.05$ was considered statistically significant.

\section{Results}

Group characteristics. The age of the patients ranged from 28 to 84 years (mean 59 years \pm 15 ). Detailed characteristics of the study group, including median values of age, height, body mass, and body mass index (BMI), divided by sex, are summarized in Table II.

There were no significant differences in the distribution of BMI categories in the study group ( $p=0.572$, FisherFreeman-Halton exact test). Normal weight was observed in 7 patients $(43.75 \%)$, including 5 males and 2 females, while a quarter of the study group was underweight ( 2 males, 2 females). Body mass index above normal was observed in 3 female and 2 male participants (31.25\% of the subjects).

End jejunostomy excretion volumes. The average 4-day stomal secretion during the first phase (supply of water without additives) was $811.9 \mathrm{ml} /$ day, and the highest and lowest daily volumes were 2,000 and $150 \mathrm{ml}$, respectively, both observed on the first day of the phase. During this stage, patients reported a thin, liquid-like consistency of the jejunal 


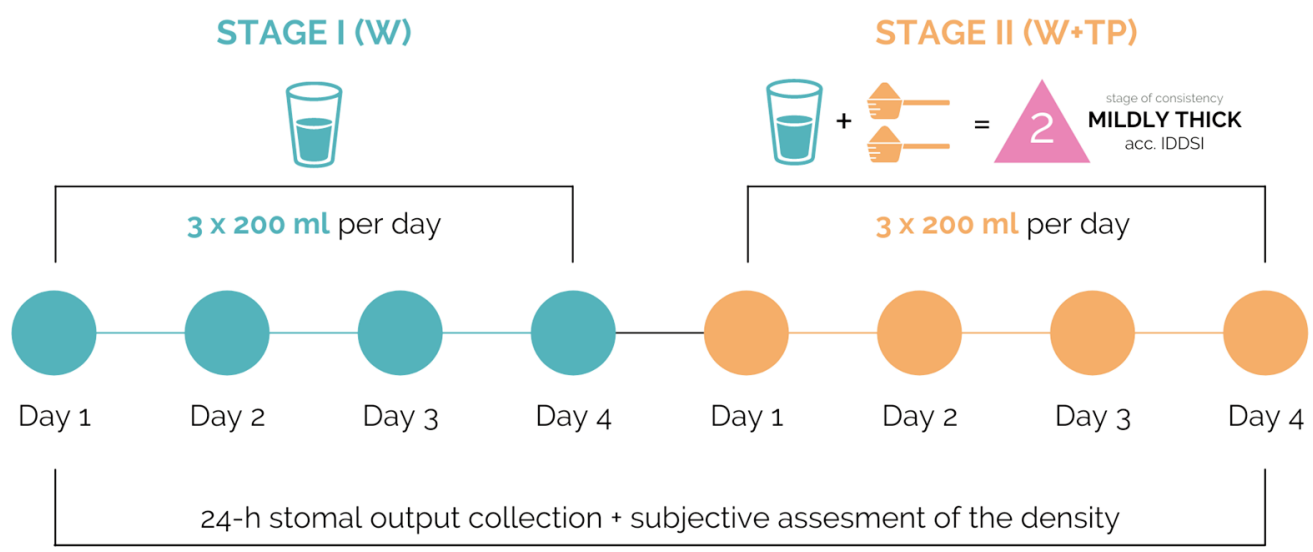

Figure 1. The scheme of thickening powder supplementation.

Table II. Group characteristics.

\begin{tabular}{|c|c|c|c|c|c|c|c|c|}
\hline & \multicolumn{2}{|c|}{ Female $(n=7)$} & \multicolumn{2}{|c|}{ Male $(n=9)$} & \multicolumn{2}{|c|}{ Total } & \multirow[t]{2}{*}{$\mathrm{z}$} & \multirow[t]{2}{*}{$p$-Value* } \\
\hline & Mdn & $\mathrm{IQR} / 2$ & Mdn & $\mathrm{IQR} / 2$ & Mdn & $\mathrm{IQR} / 2$ & & \\
\hline Age $[y]$ & 59.00 & 13.50 & 64.00 & 5.50 & 63.50 & 9.50 & -0.106 & 0.918 \\
\hline Body mass $[\mathrm{kg}]$ & 66.00 & 13.50 & 64.00 & 6.00 & 64.50 & 9.00 & -0.318 & 0.758 \\
\hline Height $[\mathrm{m}]$ & 1.65 & 0.03 & 1.70 & 0.02 & 1.68 & 0.03 & -2.824 & 0.002 \\
\hline BMI $\left[\mathrm{kg} / \mathrm{m}^{2}\right]$ & 25.15 & 4.85 & 21.97 & 1.64 & 22.06 & 3.09 & 0.318 & 0.758 \\
\hline
\end{tabular}

Mdn: Median; IQR/2: semi-quartile range. *Mann-Whitney $U$-test with continuity correction.

Table III. End jejunostomy excretion volumes after drinking water and the mixture of water with thickening powder.

\begin{tabular}{|c|c|c|c|c|c|c|c|}
\hline & \multicolumn{2}{|c|}{ Water $(n=16)$} & \multicolumn{2}{|c|}{ Water + thickening powder $(n=16)$} & \multirow[t]{2}{*}{$\mathrm{z}$} & \multirow[t]{2}{*}{$p$-Value* } & \multirow[t]{2}{*}{$\eta^{2}$} \\
\hline & Mdn & $\mathrm{IQR} / 2$ & Mdn & $\mathrm{IQR} / 2$ & & & \\
\hline Day 1 & 825.0 & 430.00 & 645.0 & 150.00 & 3.209 & 0.001 & 0.644 \\
\hline Day 2 & 650.0 & 375.00 & 642.5 & 273.75 & 2.792 & 0.005 & 0.487 \\
\hline Day 3 & 935.0 & 350.00 & 450.0 & 230.00 & 3.464 & 0.001 & 0.750 \\
\hline Day 4 & 900.0 & 387.50 & 500.0 & 182.50 & 3.103 & 0.002 & 0.602 \\
\hline Mean & 811.9 & 337.50 & 550.0 & 215.63 & 3.154 & 0.002 & 0.622 \\
\hline
\end{tabular}

Mdn: Median; IQR/2: semi-quartile range. *Wilcoxon signed-rank test.

contents and complained of frequent detachment of the stoma bag while it was partially filled. In the second phase - during administration of a composition of water and TP - the average 4-day stoma output volume decreased significantly $(p=0.002)$ to $550.0 \mathrm{ml}$ with maximum and minimum values of $975 \mathrm{ml}$ (day II) and $100 \mathrm{ml}$ (day I and III), respectively. In one case, an increase in jejunal excretion was observed after ingestion of water with TP. According to the reports of other patients $(n=15)$, the consistency of the ostomy output was thicker compared to the days when they drank clear water. They also needed to change the stoma bag less frequently. Differences in volumes of end jejunostomy discharge were observed when comparing 4-day mean values for stages as well as median values between days. Detailed results of the study are presented in Table III, Figure 2 and Figure 3.

\section{Discussion}

This preliminary study investigated the potential use of thickening powders in patients with high-output end jejunostomy. It is known that solid food stimulates stoma output less than liquids (especially unbalanced). Thickening and 


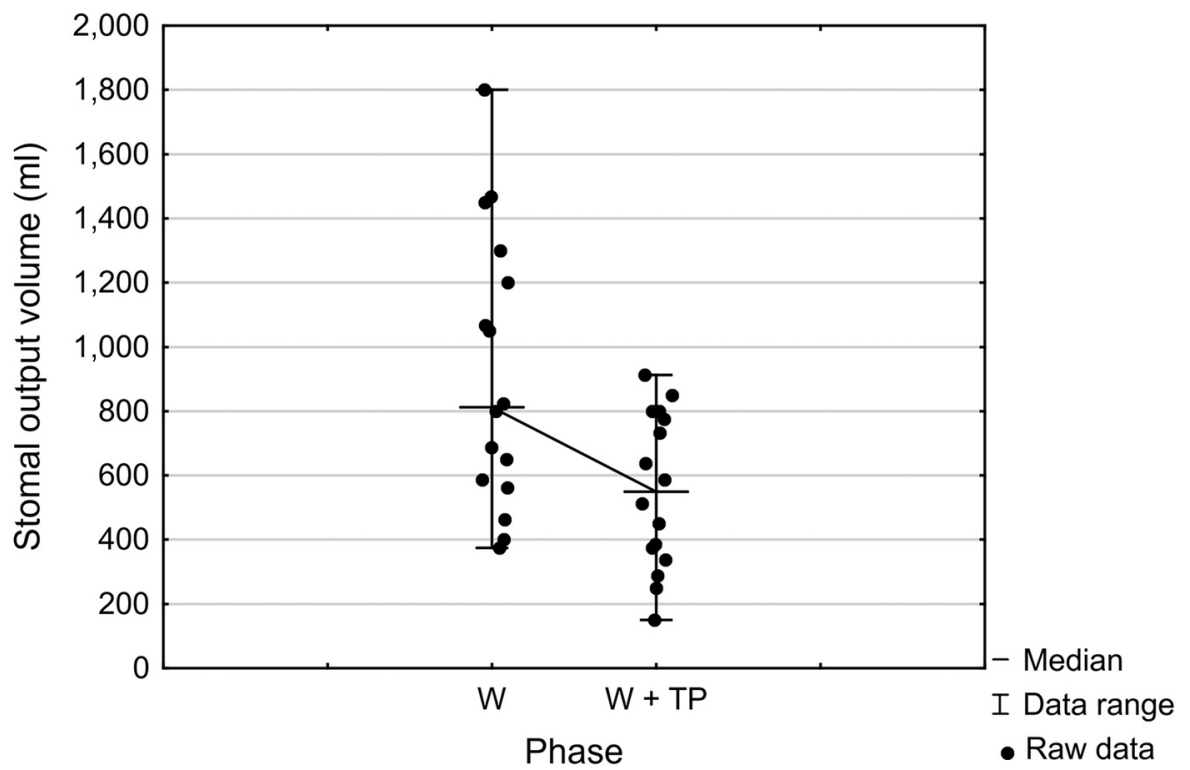

Figure 2. The comparison of stomal output volume $(\mathrm{ml})$ between the first $(W)$ and the second $(W+T P)$ phase. W: Water; TP: thickening powder.

sodium addition prolong contact with the mucosa and decrease mucosal secretion, resulting in an increase in net absorption. We reported a significant reduction $(550.0 \mathrm{vs} .811 .9 \mathrm{ml} / \mathrm{d})$ in stoma output volume after administration of water mixed with thickening powder compared with drinking plain water without any additives. To our knowledge, there are no other studies investigating this approach with which to compare the results.

About 8-10 1 of fluid, including saliva, gastric juice, pancreaticobiliary and intestinal secretions, pass through the gastrointestinal tract daily, with only 1.51 of these fluids entering the colon $(4,19)$. Therefore, the high excretion in patients with a stoma located in the proximal $100 \mathrm{~cm}$ of the jejunum contributes not only to losses of water, but also of proteins, bile salts, sodium, chloride, and HCO3-, as well as other important macro- and micronutrients $(4,20,21)$. In addition, digestion and absorption require a high expenditure of energy and protein (especially in the upper small intestine) to enable motility, enzyme synthesis, and active absorption, among other functions (20).

Nutritional management of HOS, reported by several authors to be most common in patients with an end jejunostomy, is becoming a topic of growing interest worldwide. In this group of patients, stoma volume increases after food and fluid intake, making it difficult to provide adequate oral nutrition without exacerbating sodium losses $(4,5)$. It is unlikely that their nutritional and fluid requirements will change over time, as there is no evidence of intestinal adaptation following the formation of a jejunostomy (22). The main goals of treatment for patients with end jejunostomy include reduction of stomal output, slowing intestinal transit, and maintaining fluid and electrolyte balance. There are no specific recommendations for acceptable limits of jejunostomy secretion, but daily volumes below 1,200-2,000 $\mathrm{ml}$ are considered more manageable (3, 9, 13, 22). The treatment of high output end jejunostomy syndrome is a complex matter that should be conducted by a multidisciplinary team of specialists with clinical experience, including surgeons, gastroenterologists, dietitians, nurses, general practitioners, psychologists, pharmacists, and physical therapists $(4,5,21,23)$. Guidelines from American Society for Parenteral and Enteral Nutrition (ASPEN) (24) recommend 35$45 \mathrm{kcal} / \mathrm{kg} /$ day and $1.5-2.0 \mathrm{~g} / \mathrm{kg} /$ day of protein. Matarese (13) recommends an intake of approximately $30-40 \%$ of energy from fat for SBS patients with end jejunostomy, which has not been shown to increase stoma excretion or provoke calcium, sodium, or magnesium losses. According to Mountford et al. (4), a high energy diet, low in fiber, vegetables, fruits, nuts, and whole grains should be introduced. Parenteral nutrition is most often required in patients with less than $75 \mathrm{~cm}$ of small bowel remaining, when energy absorption is less than $1 / 3$ of oral energy intake (25). In our recent study, we have shown that unrestricted oral intake in patients with high-output end jejunostomy leads to uncontrolled protein and energy deficiency, dehydration, renal and hepatic insufficiency and prolongation of time to reconstructive surgery (20). However, the beneficial effects of enteral feeding on stimulation of the enteric nervous system and secretion of enterohormones, as well as the psychosocial aspect of being able to eat orally, should not be underestimated. Therefore, an important principle in the treatment of HOS should be to find a way to allow oral intake without provoking extensive faecal losses. The results obtained 


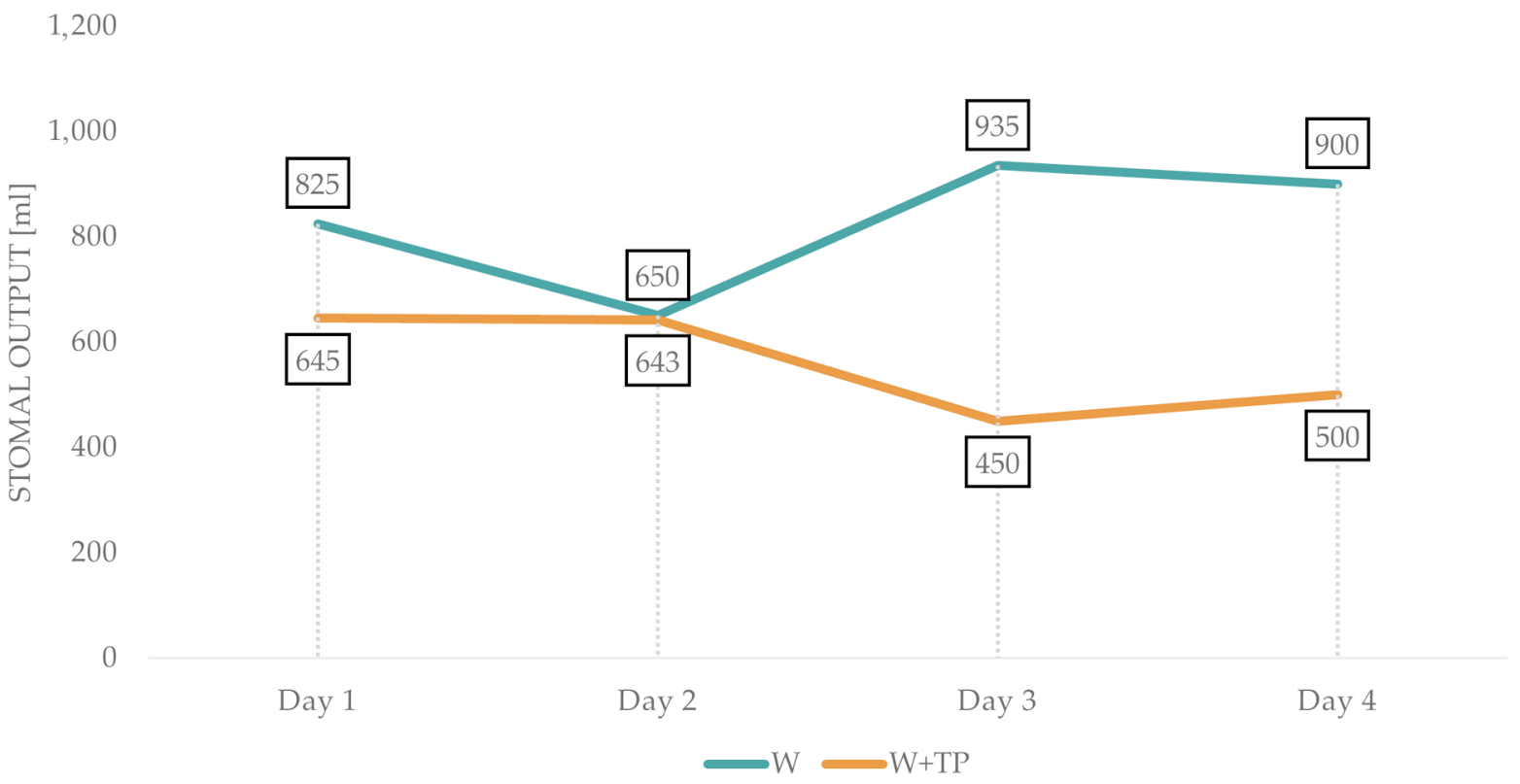

Figure 3. Median volumes of stoma excretion $(\mathrm{ml})$ on the same days of both phases.

in this study suggest that altering the consistency of liquids with thickening powder may be a sufficient way to achieve this goal.

According to available literature, patients with a high output stoma should be advised to limit their intake of hypotonic and hypertonic fluids to $1,000 \mathrm{ml}$ per day $(3,4,21)$. Restricting oral intake of hypotonic beverages can be challenging for patients because drinking seems to be a natural response to thirst. Unfortunately, some patients with HOS are mistakenly advised by healthcare professionals to drink more water or other hypotonic fluids to compensate for high stoma excretion, leading to further disturbances in water and electrolyte balance $(5,21)$. To meet fluid requirements, it is recommended to drink oral rehydration solutions (ORS) with a sodium concentration greater than $90 \mathrm{mmol} / \mathrm{l}$, such as St. Marks solution or Glucodrate ${ }^{\circledR}$, a pre-flavoured ORS recently presented by Culkin et al. $(3,4,26)$. Such concentration prevents sodium from being drawn from the plasma into the intestinal lumen. It has been hypothesised that the decrease in jejunal outflow volume that we observed when patients ingested water with thickening powder may be related to the salt content of the TP. It contains $3.8 \mathrm{~g}$ of salt per $100 \mathrm{~g}$, therefore patients consumed a daily dose of $0.7 \mathrm{~g}$ per $600 \mathrm{ml}$ of the mixture of water and thickening powder. This means that the sodium concentration in the mixture was much lower than in ORS and therefore, does not support the thesis that there is a relationship between reduction in stoma output and the sodium content of TP. This leads to the suggestion that the results are directly related to the consistency of the mixture, but the exact mechanism remains unclear. A decrease in discharge from the stoma by an average of $400 \mathrm{ml}$ indicates an increase in absorption, which in turn allows an increase in diuresis by the corresponding volume of urine $(3,20)$. Progressive renal failure or acute renal failure in patients with HOS without parenteral support is a typical complication of structural type I SBS. Adequate use of a thickening agent may prevent chronic parenteral nutrition or at least reduce the need for PN.

\section{Conclusion}

Our study has several limitations, such as its retrospective nature and a rather small and heterogeneous patient population. In addition, the study did not include any measures of dehydration or sodium and fluid balance. However, despite these limitations, our results show a positive effect of thickening fluids with thickening powder on the volume and consistency of intestinal discharge in patients with high-output end jejunostomy and suggest that the use of thickening powder could potentially be beneficial in the nutritional management of HOS. These preliminary results indicate the need for further research on this topic.

\section{Conflicts of Interest}

The Authors declare no conflicts of interest in relation to this study.

\section{Authors' Contributions}

Conceptualization: J.S. and Z.Z. and K.D.; methodology: Z.Z., M.P. and J.S.; data collection: Z.Z. and K.D.; formal analysis: M.P. and 
Z.Z.; writing - original draft preparation: Z.Z.; writing - review and editing: J.S., Z.Z., K.D., M.P. and O.M.; supervision: J.S. and O.M.; critical review, all Authors. All Authors have read and agreed to the published version of the manuscript.

\section{References}

1 Jeppesen PB: Spectrum of short bowel syndrome in adults: intestinal insufficiency to intestinal failure. JPEN J Parenter Enteral Nutr 38(1 Suppl): 8S-13S, 2014. PMID: 24486858. DOI: 10.1177/0148607114520994

2 Tappenden KA: Pathophysiology of short bowel syndrome: considerations of resected and residual anatomy. JPEN J Parenter Enteral Nutr 38(1 Suppl): 14S-22S, 2014. PMID: 24500909. DOI: $10.1177 / 0148607113520005$

3 Pironi L, Arends J, Bozzetti F, Cuerda C, Gillanders L, Jeppesen PB, Joly F, Kelly D, Lal S, Staun M, Szczepanek K, Van Gossum A, Wanten G, Schneider SM and Home Artificial Nutrition \& Chronic Intestinal Failure Special Interest Group of ESPEN: ESPEN guidelines on chronic intestinal failure in adults. Clin Nutr 35(2): 247-307, 2016. PMID: 26944585. DOI: 10.1016/j.clnu.2016.01.020

4 Mountford CG, Manas DM and Thompson NP: A practical approach to the management of high-output stoma. Frontline Gastroenterol 5(3): 203-207, 2014. PMID: 28839771. DOI: 10.1136/flgastro-2013-100375

5 Baker ML, Williams RN and Nightingale JM: Causes and management of a high-output stoma. Colorectal Dis 13(2): 191-197, 2011. PMID: 19888956. DOI: 10.1111/j.1463-1318.2009.02107.x

6 Nightingale JM, Kamm MA, van der Sijp JR, Ghatei MA, Bloom SR and Lennard-Jones JE: Gastrointestinal hormones in short bowel syndrome. Peptide YY may be the 'colonic brake' to gastric emptying. Gut 39(2): 267-272, 1996. PMID: 8977342. DOI: $10.1136 /$ gut.39.2.267

7 Nightingale JM, Kamm MA, van der Sijp JR, Morris GP, Walker ER, Mather SJ, Britton KE and Lennard-Jones JE: Disturbed gastric emptying in the short bowel syndrome. Evidence for a 'colonic brake'. Gut 34(9): 1171-1176, 1993. PMID: 8406148. DOI: $10.1136 /$ gut.34.9.1171

8 Ławiński M, Haraszczuk D, Gradowska A, Kostro JZ, Bzikowska A and Sobocki J: Strategies for early metabolic disturbances in patients with an end jejunostomy or end ileostomy. Experience from a specialized Home Parenteral Nutrition (HPN) center. Prz Gastroenterol 12(2): 111-117, 2017. PMID: 28702099. DOI: 10.5114/pg.2016.58599

9 Adaba F, Vaizey CJ and Warusavitarne J: Management of intestinal failure: the high-output enterostomy and enterocutaneous fistula. Clin Colon Rectal Surg 30(3): 215-222, 2017. PMID: 28684940. DOI: $10.1055 / \mathrm{s}-0037-1598163$

10 O'Keefe SJ, Buchman AL, Fishbein TM, Jeejeebhoy KN, Jeppesen PB and Shaffer J: Short bowel syndrome and intestinal failure: consensus definitions and overview. Clin Gastroenterol Hepatol 4(1): 6-10, 2006. PMID: 16431298. DOI: 10.1016/j.cgh.2005.10.002

11 Amiot A, Messing B, Corcos O, Panis Y and Joly F: Determinants of home parenteral nutrition dependence and survival of 268 patients with non-malignant short bowel syndrome. Clin Nutr 32(3): 368-374, 2013. PMID: 22992308. DOI: 10.1016/j.clnu.2012.08.007

12 Billiauws L, Maggiori L, Joly F and Panis Y: Medical and surgical management of short bowel syndrome. J Visc Surg 155(4): 283291, 2018. PMID: 30041905. DOI: 10.1016/j.jviscsurg.2017.12.012
13 Matarese LE: Nutrition and fluid optimization for patients with short bowel syndrome. JPEN J Parenter Enteral Nutr 37(2): 161170, 2013. PMID: 23264168. DOI: 10.1177/0148607112469818

14 Gallegos C, Brito-de la Fuente E, Clavé P, Costa A and Assegehegn G: Nutritional aspects of dysphagia management. Adv Food Nutr Res 81: 271-318, 2017. PMID: 28317607. DOI: 10.1016/bs.afnr.2016.11.008

15 Steele CM, Alsanei WA, Ayanikalath S, Barbon CE, Chen J, Cichero JA, Coutts K, Dantas RO, Duivestein J, Giosa L, Hanson B, Lam P, Lecko C, Leigh C, Nagy A, Namasivayam AM, Nascimento WV, Odendaal I, Smith CH and Wang H: The influence of food texture and liquid consistency modification on swallowing physiology and function: a systematic review. Dysphagia 30(1): 226, 2015. PMID: 25343878. DOI: 10.1007/s00455-014-9578-x

16 National Health and Nutrition Examination Survey (NHANES). Anthropometry Procedures Manual. 2007. Available at: https://www.cdc.gov/nchs/data/nhanes/nhanes_07_08/manual_an .pdf [Last accessed on January 6, 2022]

17 Lipschitz DA: Screening for nutritional status in the elderly. Prim Care 21(1): 55-67, 1994. PMID: 8197257.

18 Cichero JA, Lam P, Steele CM, Hanson B, Chen J, Dantas RO, Duivestein J, Kayashita J, Lecko C, Murray J, Pillay M, Riquelme L and Stanschus S: Development of international terminology and definitions for texture-modified foods and thickened fluids used in dysphagia management: The IDDSI framework. Dysphagia 32(2): 293-314, 2017. PMID: 27913916. DOI: $10.1007 / \mathrm{s} 00455-016-9758-y$

19 Kiela PR and Ghishan FK: Physiology of intestinal absorption and secretion. Best Pract Res Clin Gastroenterol 30(2): 145-159, 2016. PMID: 27086882. DOI: 10.1016/j.bpg.2016.02.007

20 Sobocki J, Zaczek Z, Jurczak P, Lachowicz K, Kunecki M, Groszek P, Majewska K, Panczyk M and Forbes A: Restricted $v$. unrestricted oral intake in high output end-jejunostomy patients referred to reconstructive surgery. Br J Nutr 125(10): 1125-1131, 2021. PMID: 32873362. DOI: 10.1017/S0007114520003360

21 Medlin S: Nutritional and fluid requirements: high-output stomas. Br J Nurs 21(6): S22-S25, 2012. PMID: 22584891. DOI: 10.12968/bjon.2012.21.Sup6.S22

22 Nightingale J, Woodward JM and Small Bowel and Nutrition Committee of the British Society of Gastroenterology: Guidelines for management of patients with a short bowel. Gut 55(Suppl 4): iv1-i12, 2006. PMID: 16837533. DOI: 10.1136/gut.2006.091108

23 Matarese LE, Jeppesen PB and O'Keefe SJ: Short bowel syndrome in adults: the need for an interdisciplinary approach and coordinated care. JPEN J Parenter Enteral Nutr 38(1 Suppl): 60S64S, 2014. PMID: 24418899. DOI: 10.1177/0148607113518946

24 Mueller CM: The ASPEN adult nutrition support core curriculum. American Society for Parenteral and Enteral Nutrition, 2017.

25 Rodrigues CA, Lennard-Jones JE, Thompson DG and Farthing MJ: Energy absorption as a measure of intestinal failure in the short bowel syndrome. Gut 30(2): 176-183, 1989. PMID: 2495238. DOI: $10.1136 /$ gut.30.2.176

26 Culkin A, Gabe SM and Nightingale JMD: A new palatable oral rehydration solution: A randomised controlled cross-over study in patients with a high output stoma. J Hum Nutr Diet 35(1): 94101, 2022. PMID: 34323341. DOI: 10.1111/jhn.12935

Received January 21, 2022

Revised February 8, 2022 Accepted February 10, 2022 